\title{
Possibilities of Energy Utilization of Waste from the Automotive Industry at Present
}

\author{
Peter Pilát ${ }^{1, *}$, and Marek Patsch ${ }^{1}$ \\ ${ }^{1}$ University of Žilina, Faculty of mechanical engineering, Department of power engineering, \\ Univerzitna 8215/1, 01026 Žilina, Slovakia
}

\begin{abstract}
The car is now a consumer product and its use has significantly decreased over the last decades. According to the sources of the Ministry of the Internal Affairs of the Slovak Republic, is to 31 January 2020 registered 3.286.258 motor vehicles and of which 2.395.362 are passenger cars, which means that per slovak citizen there is something below 0.5 of passenger vehicle. Used passenger cars make up the largest part of the car waste. This paper deals with how the waste from cars after their lifecycle in currently operating energy facilities.
\end{abstract}

\section{Introduction}

The sector of energy evaluation of waste has undergone rapid technological development over the last 10 to 15 years. Many of the changes in this sector have been triggered by sector-specific legislation, which has led in particular to a reduction in air emissions from individual plants. The development process is continuous, with the development of techniques in this sector that limit costs and at the same time maintain or improve care for the environment. The aim of waste incineration, together with most waste management methods, is to treat waste in such a way as to reduce its volume and hazard, while trapping (and thus concentrating) or decomposing potentially hazardous substances. Incineration processes can also be a means of recovering energy, minerals or chemicals contained in waste. Product of pyrolysis is more valuable fuel.

\section{Energy usable waste from automotive}

Plastics: usable parts are used as spare parts in direct sales to customers. According to the agreement of the Association of European Manufacturers, each plastic part in a car weighing more than $100 \mathrm{~g}$ is marked with a code that makes it possible to identify the type of plastic and thus make it easier to ensure recycling or decide on its suitability for energy use. Residues from cable scrap can also be included in the category of plastic waste, these are formed by cable insulation, terminals, connectors, etc.

\footnotetext{
${ }^{*}$ Corresponding author: peter.pilat@,fstroj.uniza.sk
} 
Rubber: used tire casings are processed by crushing. Rubber crumb is used as a substitute for conventional fuels, for example in cement plants. Old tires contain $18-20 \%$ steel cord and fabric.

Seat padding: Polyurethane foam is torn and, after re-pressing, used as a thermal or cushioning material, or as a replacement for a green roof substrate and as part of a "Solid Alternative Fuel.

Waste oil and leather: they are suitable for energy use - incineration in a municipal impact incinerator or other technology with a combustion plant (e.g. cement furnace).

Synthetic fabrics and covers: make up approximately $2.5 \%$ of the weight of the vehicle, after tearing they are suitable as a semi-finished product for collection for further processing or for energy use.

Other unusable waste: depending on its composition, it can still be used for energy using suitable technology (e.g. pyrolysis) and only in the last step are the residues destined for disposal to a municipal waste landfill.

\section{Reasons for energy recovery of waste from the automotive industry}

Energy recovery of waste from the automotive industry brings great benefits:

- Obtaining the so-called "Alternative energy", which saves primary energy sources,

- The possibility of excluding waste from the automotive industry from landfills,

- The possibility of disposing of residual waste from the automotive industry (waste after separation of secondary raw materials),

- Minimization of the volume of waste after final disposal (only up to $10 \%$ of ash remains from the waste, depending on the composition of the original waste before energy recovery).

Disadvantages of energy recovery of waste from the automotive industry:

- The waste must be suitably treated before energy recovery according to the used energy recovery technology,

- It is necessary to ensure continuous measurement of the composition of waste and, alternatively, to change the settings of the conditions of energy recovery of waste,

- At the disposal of harmful emission constituents, it is necessary to use investment intensive additional equipment.

The ultimate technologies for energy recovery of waste from the automotive industry are incineration, gasification, pyrolysis and plasma gasification, most preferably is, if all technologies are in conjunction with cogeneration. Cogeneration production of heat and electricity at least partially covers the high energy intensity of car wreck recycling (the input of technological lines, especially shredding is several hundred kilowatts).

\section{Possible ways of energy recovery of waste from the automotive industry}

Incineration is recommended by EU directives as one of the methods of disposing of waste from the automotive industry, which, under specified conditions, meets strict environmental protection requirements. The incineration of waste can be considered advantageous from the point of view of its energy use and is justified especially in the case of such waste that burns without additional fuel. It is not always possible to ensure this condition (either from the point of view of a small amount of waste or from the point of view of the chemicalphysical properties of the waste), therefore it is appropriate to create fuel-waste mixtures most often together with conventional fuels. In the case of solid waste (plastics, rubber, 
textiles, paper, etc.), these are mixtures together with coal, biomass, etc., thus creating a solid alternative fuel. Solid alternative fuel is a material that results from the separation and treatment of waste materials composed of plastics, paper, textiles, rubber and other combustible substances. It is a crushed mixture of substances from selected industrial and sorted municipal waste, which has a clearly defined composition of substances and a determined particle size distribution, which results in a fuel mixture of regularly controlled parameters with a minimum content of hazardous waste and waste contaminated with hazardous substances. For the production of solid alternative fuel, the physical and chemical properties of input raw materials and types of waste according to the Waste Catalog, which meet the requirements of the plant in which they will be incinerated, ie. their operation will be in accordance with the valid legal regulation in this area of environmental protection. More types of waste are usually used for the production of solid alternativ fuel, e.g. mixed plastics, paper, cardboard, textiles, textile fiber, carpets, rubber, tires, wood, chipboard. The components of waste with high calorific value are especially suitable for energy use, for example: dry paper - $17 \mathrm{MJ} \cdot \mathrm{kg}^{-1}$, rubber - $35 \mathrm{MJ} . \mathrm{kg}^{-1}$, PET bottles - $23 \mathrm{MJ} . \mathrm{kg}^{-1}$, plastic from recycling - $25 \mathrm{MJ} . \mathrm{kg}^{-1}$, plastic foil - $42 \mathrm{MJ} . \mathrm{kg}^{-1}$, hard

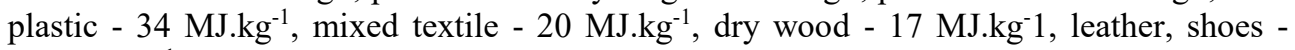
$19 \mathrm{MJ} . \mathrm{kg}^{-1}$. The advantage of combustion a solid alternative fuel lies mainly in the properties of the resulting material, where the calorific value is comparable to high-quality brown coal, while the composition and quality of the input materials can achieve a calorific value comparable to black coal and at the same time reduce the amount of harmful substances.

All methods of incineration of waste from the automotive industry must in all circumstances meet emission limits - gaseous emissions (CO, $\mathrm{SO}_{2}, \mathrm{NOx}$, but also, for example, dioxins, furans, unlimited pollutants, etc.) and particulate matters.

Municipal and industrial waste incinerators (eg from the automotive industry) are equipped with constantly modernizing incineration technologies:

- Combustion on different types of grates,

- Incineration in rotary kilns,

- Fluidized bed combustion. and flue gas cleaning technologies:

- Dry flue gas cleaning method,

- Semi-dry flue gas cleaning method,

- Wet flue gas cleaning method,

- SNCR technology,

- DeNOx system and DeDiox system, in a locally and technically suitable combination.

The combustion sector has undergone rapid technological development over the last 10 to 15 years. Many of the changes in this sector have been triggered by sector-specific legislation, which has resulted in particular in the reduction of air emissions from individual plants. The development process is continuous, with the development of techniques in this sector that limit costs and at the same time maintain or improve care for the environment. The aim of waste incineration, together with most waste management methods, is to treat waste in such a way as to reduce its volume and hazard, while trapping (and thus concentrating) or decomposing potentially hazardous substances. Incineration processes can also be a means of recovering energy, minerals or chemicals contained in waste.

After combustion, gasification has a long history of development, which in the past was most famous for the process of carbonization of biomass in order to obtain charcoal. Gasification is the conversion of a solid by gasification reactions into synthesis gas, which is used energetically either directly by combustion or after purification and transport through a gas pipeline at the destination. Disposal of some types of waste by gasification has several advantages over traditional incineration methods, such as the possibility of partially securing society's energy needs by gasifying less valuable fossil fuels and waste 
and increasing the energy self-sufficiency of countries without quality fossil fuel resources. Waste gasification is a complex process involving many physical and chemical reactions. Liquid and solid wastes, which contain a significant proportion of bound carbon and less hydrogen, react with a substoichiometric amount of oxidizing agent. Waste gasification takes place in a reducing environment, similar to pyrolysis, but at higher temperatures and by the action of gasifiers, e.g. by the action of an oxygen-vapor mixture. One of the fundamental differences between gasification and pyrolysis is that fixed carbon also passes into the gas phase during gasification. The possibilities of using such technology for energy recovery of waste are promising, the heterogeneous composition of the waste batch is especially problematic. In simple terms, the whole gasification technology can be described as follows: the waste is placed in a gasifier, where a mixture of gases is formed and the second product is ash, slag and metals, after gas purification, the purified gas is used for energy either it is not absolutely necessary to purify the resulting gas mixture). Purification of the gas removes the escape of solids and condensed tar. Parameters that most influence the course of waste gasification:

- Reactor temperature - an important operating parameter, the temperature profile in the reactor is a function of several parameters, such as the equivalent ratio (ratio of oxygen volume involved in the oxidation process of thermal treatment of waste and oxygen volume required for complex stoichiometric oxidation), residence time, chemical energy of waste, composition and inlet temperature of the dosed waste, thermal insulation of the reactor, etc.,

- Residence time - the residence time of the processed type of waste in the reaction chamber of the gasification plant is influenced by the type and design of the reactor, qualitative properties of the input raw material, temperature in the reaction chamber, waste treatment method, etc.,

- Composition and physical parameters of waste - transformation of waste into usable energy is influenced by specific properties of waste, they are mainly moisture content, ash content and volatile matter content, bulk density, grain size, elemental composition, calorific value, contaminant content,

- The inlet temperature of the waste material and the outlet temperature of the gasification products - have a significant effect on the mass and energy balance of the reactor,

- Operational and performance parameters - it is important to harmonize and determine the right combination of operating conditions to create a certain treatment system for different types of waste.

Pyrolysis and its use in the energy recovery of waste plastics is one of the most advantageous methods. Pyrolysis is the heat treatment of waste materials in a pyrolysis furnace or reactor at a temperature of 250 to $1650{ }^{\circ} \mathrm{C}$ without access to air, or with limited access of air and at reduced atmospheric pressure. Pyrolysis decomposition results in liquids (pyrolysis oil) and gaseous substances (pyrolysis gas). The material input is waste plastics, which for any reason cannot be further recycled. The resulting product is a fuel, the final quality of which is determined by the quality of the feed to the pyrolysis reactor. Technologies for processing plastic waste into fuel oils have the potential to solve two major problems today - the lack of fossil fuels and the production of non-repairable plastic waste. The process of pyrolysis processing of plastics consists in liquefaction, pyrolysis and catalytic splitting of plastics, in which waste plastics are converted into liquid hydrocarbons suitable as fuel (plastics are converted into "original" material). In this way, it is possible to process almost all plastics that otherwise end up in landfills without recovery. The gases formed during pyrolysis condense in a specially designed condensing system to form aliphatic and cyclic-aliphatic and aromatic hydrocarbons. The resulting mixture essentially corresponds to petroleum distillate. The density as well as other properties of this fuel are 
similar to those of diesel, the resulting fuel has absolutely the same energy potential, but from the point of view of ecology with significantly lower emissions. The obtained fuel oil can be used as a fuel for internal combustion engines, generators, boilers and industrial burners, or is used as a secondary raw material for the production of benzene, toluene, etc. Approximately 0.9 litres of fuel can be obtained from $1 \mathrm{~kg}$ of plastics if polyolefins such as polyethylene (PE) and polypropylene (PP) or polystyrene (PS) are processed. Pyrolysis is a promising technology, the advantage of this energy recovery technology is the fact that it can process a wide range of waste, even polluted, because e.g. most heavy metals pass into solid pyrolysis residues and do not enter the pyrolysis oil or gas and thus the gaseous emissions from combustion. The solid residue from the pyrolysis reactor represents approximately $1 / 3$ of the original weight of dry waste when using municipal waste and $1 / 10$ of the original weight of dry waste when using plastic waste. This solid residue after carbonization falls into a cooling trough, where it is indirectly cooled by process water. It is then transported for sorting on sieves, where the metal residue (ferrous and non-ferrous metals) and mineral fractions (glass, etc.) are separated. The sub-sieve fraction containing carbon is ground to dust and transported to the combustion chamber. From the underside of the combustion chamber, where the temperature is $1300{ }^{\circ} \mathrm{C}$, liquid slag flows into the aqueous granulation bath. Pyrolysis is carried out in pyrolysis chambers or fluidized bed and rotary kilns. The furnaces can be heated from the outside through the furnace shell or from the inside with hot inert gas (nitrogen, ...), to accelerate the pyrolysis, flue gases from the boiler or from the gasifier are fed into the pyrolyzer. The realized pyrolysis units are basically two-stage waste incinerators, the first stage of which is pyrolysis and the second oxidation.

\section{Possibilities of energy recovery of waste from the automotive industry in the Slovak Republic at present}

At present, it is possible in the Slovak Republic to use heat sources for central heat supply for energy recovery of waste from the automotive industry, which are intended for combined heat and power generation, municipal waste incinerators, cement industry and plants that process plastics using pyrolysis.

In Slovakia we have two municipal waste incinerators, one operation is in Košice and the other in Bratislava, where is possible to combust all types of waste, the cement industry, where they are well processed for example tires and the heat sources for central heat supply which are in almost every city, where it is justified to burn solid alternative fuel. Pyrolysis is used by only a few small plants and only one larger one is near the town Lučenec.

\section{Conclusion}

There are many methods for energy recovery of waste, but each method has a different degree of reliability and a different degree of suitability for each type of waste. Therefore, our task is to constantly improve these methods and determine their suitability and advantage for individual types of waste.

This article was created within project UNIVNET č. 0201/0004/20. 


\section{References}

1. M. Vantúch, K. Kaduchová, R. Lenhard, AIP Conference Proceedings 1745, 020063 (2016)

2. P. Durcanský, J. Jandačka, A. Kapjor, Determination of Initial Conditions for Heat Exchanger Placed in Furnace by Burning Pellets, AEaNMiFMaE (2014)

3. M. Holubčík, N. Kantová, J. Jandačka, Z. Kolková, Alternativ solid fuels combustion in small heat source, MATEC Web of Conferences 168, 08002 (2018)

4. R. Nosek, S. Gavlas, R. Lenhard, M. Malcho, V. Sedlak, and S. Teie, AIP Conference Proceedings 1917, 030001 (2017)

5. K. Heinzelová, V. Lunkin, M. Dudrik. J. Kizek, Materials Science and Technology 1 (2013) 